\title{
Do Self-Concepts and Significant Other Concepts Predict Health-Related Quality of Life?
}

\author{
Silvia Maués Santos Rodrigues ${ }^{1}$, Fernando Augusto Ramos Pontes', \\ Janari da Silva Pedroso ${ }^{2}$ \\ ${ }^{1}$ Theory and Research of Behavior Post Graduation Program, Federal University of Pará, Belém, Brazil \\ ${ }^{2}$ Psychology Post Graduation Program, Federal University of Pará, Belém, Brazil \\ Email: silviamaues@ufpa.br
}

Received 7 September 2015; accepted 10 October 2015; published 13 October 2015

Copyright $@ 2015$ by authors and Scientific Research Publishing Inc.

This work is licensed under the Creative Commons Attribution International License (CC BY).

http://creativecommons.org/licenses/by/4.0/

(c) () Open Access

\section{Abstract}

This article concerns the relations between self-concepts and concepts of significant others and, health related quality of life (HRQOL) in adolescents from different backgrounds. It was introduced that both constructs highlighted their importance to adolescents health status and, with a sample of 1.082 adolescents who answered two instruments aimed at each of these constructs, the Family Identification Test (FIT) and KIDSCREEN-27, respectively, it was sought to an analysis model to answer the research questions. In the first part, the factor structure of the instruments through confirmatory factor analysis (CFA) was investigated in order to confirm the factor structure of the two constructs. In the second part, a Structural Model through causal pathways between the latent variables and analysis of their significance through $\mathrm{Z}$ tests to critical ratios was developed. The reported evidence supports the conclusions that identity processes experienced by adolescents especially, the actual self-concept, has a significant impact on their health and wellbeing.

\section{Keywords}

Self-Concept, Other's Concept, HRQoL, FIT, Structural Equation Modeling

\section{Introduction}

During the adolescence, it can be considered that maladaptive behavior and self-concept converge in an important way (Ybrandt, 2008). Despite that, the vast majority of adolescents go through this phase of development 
without too many surprises. However, some will experience psychological and behavioral problems. Thus, the central task in adolescence to establish a stable and coherent identity (Erikson, 1968/1994) may face difficulties and the self-concept plays an important role in this scenario.

The self-concept is structured from the individual and the others current experiences (assimilation) and, these experiences can be changed based on past experiences (accommodation), producing a scheme in a relatively high level of generalization. So, each developmental challenge related to individual experience can promote changes in self-concept and characterize contextual self-schemes (Remschmidt \& Mattejat, 1999). Theorists of social psychology had already noted that just might be the sense of self if there were a corresponding sense of the other members of their social group. That means, the social relations and the role that someone plays in society will constitute the person (Mead, 1934/2009).

Current and past experiences can be complicated by unfavorable conditions present in the social context of adolescents such as for example, unsafe sexual practices (Taquette, Vilhena, \& Paula, 2004), early pregnancy (Chalem et al., 2007; Rodrigues, Almeida, \& Ramos, 2011), use and abuse of substances (Humensky, 2010; Lemstra et al., 2008; Tavares, Béria, \& Lima, 2004), poor eating habits (Levy et al., 2010; Veiga, Cunha, \& Sichieri, 2004), lack of exercise (Sacker \& Cable, 2006; Seabra, Mendonça, Thomis, Anjos, \& Maia, 2008), family violence, sexual abuse (Teixeira \& Taquette, 2010), severe physical punishment (Sá, Bordin, Martin, \& Paula, 2010), that may impact on their mental health (Borges \& Werlang, 2006; Cruzeiro et al., 2008; Jatobá \& Bastos, 2007) and can be considered risk factors to their full development, including their self-concept and self-esteem.

Rogers (1961) pointed out that the self-concept played an important role in regulating behavior, determining which aspects of the experience were admissible to consciousness and what aspects needed to be repressed to minimize conflict with himself or with others. If particular aspects of self-concept are considered acceptable or not is partly determined by the nature of one's interactions with others including the experience of being conditionally considered by them. Moreover, in agreement with other authors (Butler \& Haigh, 1954), he argued that it is possible to put in correlation aspects of actual self with the ideal self, using appropriate techniques to evaluate discrepancies in self-concept before and after therapy and convert the phenomenological data into elements, objectives and analyzable, useful to evaluate outcomes (Rogers, 1961/2012).

Some authors have highlighted the importance of others and the environment experienced by the person for the self-concept and the well-being (Craven \& Marsh, 2008; Locke, 2006; Lynch, 2004; Lynch, 2014; Lynch, La Guardia, \& Ryan, 2009; Rogers \& Dymond, 1954) and self-concept measures using the Big Five Model (BFM) could be analyzed in its relations with the well being (Lynch et al., 2009). Others studies have investigated the relationship between self-concept and health-related quality of life (Beasley \& Garn, 2013; Fonseca, 2013; Barnett \& Hunter, 2012; Martinez, Martin, \& Dowson, 2006). Additionally, several studies have shown associations of different facets of the personality with dimensions of quality of life in different groups: healthy adult informants (Costa \& McCrae, 1980; Siegler \& Brummett, 2000; Yamaoka et al., 1998), patients with somatic diseases (Aarstad, Aarstad, \& Olofsson, 2008; Boye et al., 2008; Gomes \& Ribeiro, 2001; Penedo et al., 2003; Yamaoka et al., 1998), patients with mental illness (Masthoff, Trompenaars, Van Heck, Hodiamont, \& De Vries, 2007; van Straten, Cuijpers, van Zuuren, Smits, \& Donker, 2007) and, young informants with somatic problems (De Clercq, De Fruyt, Koot, \& Benoit, 2004; Van De Ven \& Engels, 2011).

Research on quality of life in children and adolescents has progressed with the understanding that it is closely related to their mental health and subjective wellbeing (Gaspar, Ribeiro, Matos, \& Leal, 2008). In research, specifically in the health field, the term "health related quality of life" (HRQoL) began to appear more frequently in the literature and its creation intended to define the focus of the quality of life for the effects of health, disease and treatments, the life of the individual (Monika Bullinger, 2002; Ferrans, Zerwic, Wilbur, \& Larson, 2005). The increasing interest in the investigation of HRQoL has provided the development of measuring instruments for this construct and several are currently available (Erhart \& Ravens-Sieberer, 2006; Gaspar, Matos, Ribeiro, \& Leal, 2006; Rajmil et al., 2012; Solans et al., 2008). Some were designed to evaluate populations with specific health problems like Haemo-Qol (specific to people with hemophilia) (Bullinger et al., 2002) and others are generic and can be used in any population of children and adolescents (Rodrigues, Pedroso, Pontes, \& Käppler, 2015). In that direction the creation of the generic instrument KIDSCREEN for the age group of 8 to 18 years sought in its self-report version, the perceptions of quality of life through the eyes of children and adolescents themselves to reveal what is important to them, including the level and determinants of their health in the context of their lives (Gaspar et al., 2008).

In this paper, it was assumed that the self-concept (and other's concept) could be understood as the cognitive 
representations (actual self-image, ideal self-image) that an individual makes of himself (and of others), which are developed from interactions (experience) of the individual with his environment and that such interactions are generalized to include all cognitions likely to become conscious, which the individual relates to himself (and to others) as individuals with their own characteristics and, in the same way, as cognitive schemes that have an emotional and motivational burden (Remschmidt \& Mattejat, 1999). From this assumption, it was hypothesized that there are relations between the self and the significant others cognitive representations and health-related quality of life.

This study used the Family Identification Test (FIT) (Remschmidt \& Mattejat, 1999) to obtain self-concepts and concepts of significant others and the generic questionnaire KIDSCREEN-27 (Ravens-Sieberer et al., 2006) to obtain HRQoL measures in a sample of adolescents from 12 to 18 years old. The methodology of the FIT involves the use of a list of adjectives and an answer format that allow self-descriptions (actual self and ideal self) and descriptions of significant others (other's concept) that enable the measurement of these concepts similarly to other studies that used BFM methodology (Lynch et al., 2009). The attributes present in FIT keep match with three (extraversion, agreeableness and neuroticism) of the five factors of the Big Five Model (McCrae \& John, 1992; Remschmidt \& Mattejat, 1999). The KIDSCREEN questionnaires resulted from a project carried out jointly with 13 European countries (Austria, Czech Republic, France, Greece, Hungary, Ireland, Poland, the Netherlands, Spain, Sweden, Switzerland, United Kingdom and Germany) which lasted for three years (20012004) and resulted in three versions of the questionnaires with 52, 27 and 10 items for children/adolescents (self-report version), and similar for parents/caregivers (proxy version). The KIDSCREEN-27 instrument, therefore, is a reduced version of the KIDSCREEN-52, from which 27 items were selected from the original version that were grouped in five dimensions with minimal loss of information and similar psychometric quality compared to the version of 52 items (Ravens-Sieberer, The KIDSCREEN Group Europe et al., 2006).

The present study aims to evaluate the impact of self-concepts (actual and ideal images) and the significant others concepts (mother image, father image, grandparent image) in the HRQoL, measured with the generic questionnaire KIDSCREEN-27 through the structural equation modeling (SEM).

This article presents the results of an empirical analysis of two stages that used a statistical methodology based on Structural Equation Modeling (SEM) to overcome such challenges. Here, the impact of self-concepts (actual and ideal) and concepts of significant other (mother's image, father's image and grandparent's image) was examined in health-related quality of life (HRQoL). This research, in particular, seeks to develop a structural model giving evidence to the relations between these two important constructs in the field of health and wellbeing.

The analysis of structural equations is described as a combination of classical techniques of factorial analysis and linear regression, differing, however, from conventional techniques in fact that its analysis is based on a theory established a priori, i.e., is from the theory that the analysis is made, while in the classical statistics, data is leading the formulation of theories. In the SEM, the theory is the engine of analysis (Marôco, 2014).

SEM provides a useful way to determine whether the observed data agree with a hypothesis $a$ priori on the impact of self-concepts and concepts of other significant in HRQoL. It has the advantage of providing a method for handling multiple, interrelated dependence relationships, providing statistical efficiency and to evaluate directly observable concepts to which respondents have about subjective assessments (Hair Jr., Black, Babin, Anderson, \& Tatham, 2006/2009).

\section{Methods}

\subsection{Participants}

Adolescents aged from 12 to 18 years old were recruited of an exploratory and cross sectional study of a multicenter Brazilian project research in four Brazilian state capitals: Brasilia, Porto Alegre, Fortaleza and Belém (Amparo et al., 2010). The data were integrated into a national database for analyzes. The sample was selected in a multistage sampling from three groups (clusters) of different backgrounds: clinical group (CG), selected in outpatient mental health services, after invitations in waiting rooms and voluntary acceptance; a group of public schools students (PG) formed from public schools with low human development index (HDI) and a group of private schools students (PrG) formed from schools with high HDI (Amparo et al., 2010; Morais, Amparo, Fukuda, \& Brasil, 2012; Rodrigues, Pedroso, Pontes, \& Käppler, 2015). In schools invitations were carried out to adolescents in classrooms. In each of the participating institutions, their directors or managers were asked to ac- 
cept the study voluntarily and signed form of consent. In all three groups, those adolescents who volunteered to participate, answered the instruments after their own signature (as well as their caregivers) in the consent form. The instruments were completed by 1.082 adolescents (53.9\% females). The mean age of adolescents from total sample was $15.30(S D=1.60)$ years old. There was no difference in age, between the sexes $t(1080)=-1.436, p$ $=0.151$. The mean ages by group were $M=15.4(S D=1.47)$ years old, $M=15.53(S D=1.61)$ years old, and $M$ $=14.49(S D=1.68)$ years old, respectively, for PG, PrG and CG and the differences were significant $[F(2$, $141.753)=29.242, p<0.001]$. ANOVA multiple comparisons performed with the post hoc Hochberg test revealed that adolescents from clinical group (CG) had mean ages significantly lower than PG (mean difference $=$ $-0.908, p<0.001$ ) and that of PrG (mean difference $=-1.036, p<0.001$ ). There was no difference between the ages for groups of students (PG and PrG) (Rodrigues, Pedroso, Pontes, \& Käppler, 2015).

It was obtained approval from the Ethics Research Committee in Human Beings of the Catholic University of Brasília (CEP/UCB No. 86/2006) and participants and institutions selected were asked to signing the term of free and informed consent stating their knowledge and acceptance of the research (Rodrigues, 2015).

\subsection{Instruments}

KIDSCREEN-27. In the first phase of the Brazilian multicenter study, self-report and proxy versions of KIDSCREEN-27 in Lusitanian Portuguese (Gaspar \& Matos, 2008) were adapted through a semantics validation process (Morais, 2008; Rodrigues, Pedroso, Pontes, \& Käppler, 2015). The answers to the 27 items were given on a five-point scale ranging from poor/never/not at all to excellent/always/extremely. The answers on five-point scales were computed as scores of Rasch scales using IBM ${ }^{\circledR}$ SPSS ${ }^{\circledR}$ syntax provided by KIDSCREEN Manual (Ravens-Sieberer et al., 2006). The instruments were administered in the researcher presence. The reference period of time was the week prior to the study (Erhart, Ottova, et al., 2009). The KIDSCREEN-27 instrument measures five dimensions of Health-Related Quality of Life (HRQoL) (Ravens-Sieberer et al., 2006): 1) Physical Well-Being (PHY) (five items): explores the level of physical activity or performance and energy, as well as the intensity at which a child or teenager feels ill and complains of poor health; 2) Psychological Well-Being (PWB) (seven items): explores positive emotions and life satisfaction, as well as the presence of feelings of loneliness and sadness; 3) Autonomy and Relationships with Parents (PAR) (seven items): explores the quality of interactions between children/adolescents and their parents (or caregivers), as if the young feels loved and supported by family. It also examines the level of autonomy as well as the quality of financial resources perceived by the young; 4) Social Support and Peer Relations (SOC) (four items): examines social relationships with friends and peers, as well as the support received and, 5) School Environment (SCH) (four items): explores the perception of the youth about their cognitive ability, learning and concentration and their feelings about school. Moreover, explores the vision of the young about their relationship with their teachers.

The Family Identification Test (FIT). This instrument was developed originally in two equivalent formats for test application—-paperboard and questionnaire—both organized based on twelve adjectives (active, talkative, calm, self-confident, independent, anxious, understanding, considerate, friendly, nervous, moody and content) that are used to assess the extent that the person perceives and identifies himself with other family members. These attributes keep match with three of the five factors of the Big Five Model, namely-extraversion, agreeableness and neuroticism (McCrae \& John, 1992) — the first two factors, due to its interactional relevance, and the latter because of its clinical significance. The extraversion factor was represented at the FIT in two distinct aspects, the social activity (active, talkative and calm) and assertiveness (self-confident, independent and anxious) (Remschmidt \& Mattejat, 1999). The FIT was translated into Brazilian Portuguese and validated, on its paperboard format (Teodoro, 2000). The questionnaire format used in this research keeps the adjustments made by Käppler (Käppler, 2004). There are two possible types of evaluation with FIT: intra-individual assessment and inter-individual. In the intra-individual level can be assessed: a) the raw scores, which are descriptions of yourself (How I am , How I want to be) and others (How is my mother, How is my father, etc.) called adjective level and b) the level of correlation, it means, similarity between descriptions of yourself and others, called identification level (self-congruence, actual and ideal identifications), which obtains the correlation measures between concepts measured on the first level (adjective) named execution variables. In the inter-individual level can be assessed: a) the level of inter-individual descriptions consistency and b) the level of inter-individual identifications consistency. The results of the correlation level were presented in a previous article (Rodrigues, Pedroso, Pontes, Käppler, \& Bucher-Maluschke, 2015). The analysis focus in this article is the first level of intra-individual assessment, i.e. the 
self-concepts (actual and ideal self) and the other's concept (mother image, father image and grandparent image) (Remschmidt \& Mattejat, 1999). Thus, the adolescent was asked to describe himself, his father, his mother and his grandfather or grandmother (grandparent) considered important. In the FIT questionnaires, the person searched must indicate to what extent the adjectives could be applied to each person described. The possible answers were given on a Likert scale of five points ranging from one "does not match" to five "match totally".

\subsection{Statistical Analysis}

The relationship between the factors of the two instruments, FIT and KIDSCREEN-27, defined a causal model with latent variables that was evaluated in two steps as described by Marôco (2014) with the IBM (c) AMOS software v. 22.0 Marôco (2014).

Step 1: Validation of measuring models through the use of CFA. The statistical analysis was designed to, in a last stage, examine relationships between the questionnaire KIDSCREEN and FIT in its intra-individual adjective level, i.e, the descriptions of himself and of others (actual and ideal self-image, mother image, father image and grandparent image). To achieve this goal, in the first stage, confirmatory factor analysis (CFA) of both constructs was carried out through usage the paths diagram, with IBM@AMOS v. 20.0 software as described in Marôco (Marôco, 2014). The composite reliability and average variance extracted (AVE) for each factor were described as in Fornell \& Larcker (Fornell \& Larcker, 1981). The existence of outliers was assessed by the Mahalanobis distance squared $\left(D^{2}\right)$ and the univariate and multivariate normality of the sample were evaluated by the skewness $(S k)$ and kurtosis $(K u)$ coefficients. As a global quality indicators of adjustment of the models were used: the $X^{2} / d f$ which absolute value is considered good, if less than 2 (Byrne, 1989); the CFI (Comparative Fit Index) (Bentler, 1990), the NFI (Normal Fit Index) (Bentler \& Bonett, 1980) and GFI (Goodness of Fit Index) (Jöreskog \& Sörbom, 1984; Tanaka \& Huba, 1985) whose values close to 1 indicate good fit and RMSEA (Root Mean Square Error of Approximation) (Browne \& Cudeck, 1993) with a value from 0.05 to 0.08 is considered a reasonable fit for a Confidence Interval $(C I)$ of $90 \%$ and $p$ value $\leq 0.05$.

Step 2: Structural Model. Corresponds to the causal pathways between latent variables and the determination of its significance through $\mathrm{Z}$ test to critical ratios (obtained by dividing the estimate of regression weight by the estimate of its standard error).

\section{Results}

\subsection{Exploring KIDSCREEN-27 Factorial Structure}

In the validation of the CFA assumptions, none of the variables showed skewness (Sk) and kurtosis (Ku) values as indicators of severe violations of the normal distribution ( $|\mathrm{Sk}|<3$ and $|\mathrm{Ku}|<7-10$ ) (Marôco, 2014). The existence of outliers was evaluated by the Mahalanobis distance square $\left(D^{2}\right)$ and several observations (54) were multivariate outliers. The analysis without these observations, did not produce significant improvements in the model, for this reason it was decided to keep all observations and make the model refinement only by analyzing the modification indices (MI). The original measurement model with all variables and all observations including outliers is in Figure 1. As can be seen the values of the adjustment quality indices are slightly apart from the values deemed acceptable $\left(X^{2} / d f<2, G F I>0.9\right.$, CFI $>0.9$, NFI $>0.9$, RMSEA < 0.05) (Marôco, 2014). Standardized factor weights for the vast majority of the items were above 0.5 except for KY27PHY1 (0.317) and KY27PAR4 (0.480) items and, all were statistically significant $(p<0.001)$.

It was obtained the improvement over the original measurement model by analyzing the modification indices (MI) sequentially. After analyzing the MI, errors associated with KY27PHY3 and KY27PHY4; KY27PWB4 and KY27PWB5; KY27PAR1 and KY27PAR2; KY27PAR3 and KY27PAR5; KY27PAR6 and KY27PAR7; KY27SOC3 and KY27SOC4 items were correlated and the obtained model can be seen on Figure 2.

The contribution of each item to the corresponding dimension was, in most cases, greater than 0.5 and all the items were statistically significant $(p<0.001$ ). The reliability of the model was evaluated by composite reliability (CR). The results showed that all dimensions presented composite reliability higher than the reference value 0.7 , whereby one can conclude that one can conclude that the instrument are reliable. With regard to individual reliability of each item, it was evaluated by squared factorial standardized weights $\left(\lambda^{2}\right)$ and, if this was greater than 0.25 , it can be said that the items are individually reliable. As can be seen in Table 1 , most of the items had a value greater than 0.25 , so it can be concluded the items displayed individual reliability. 


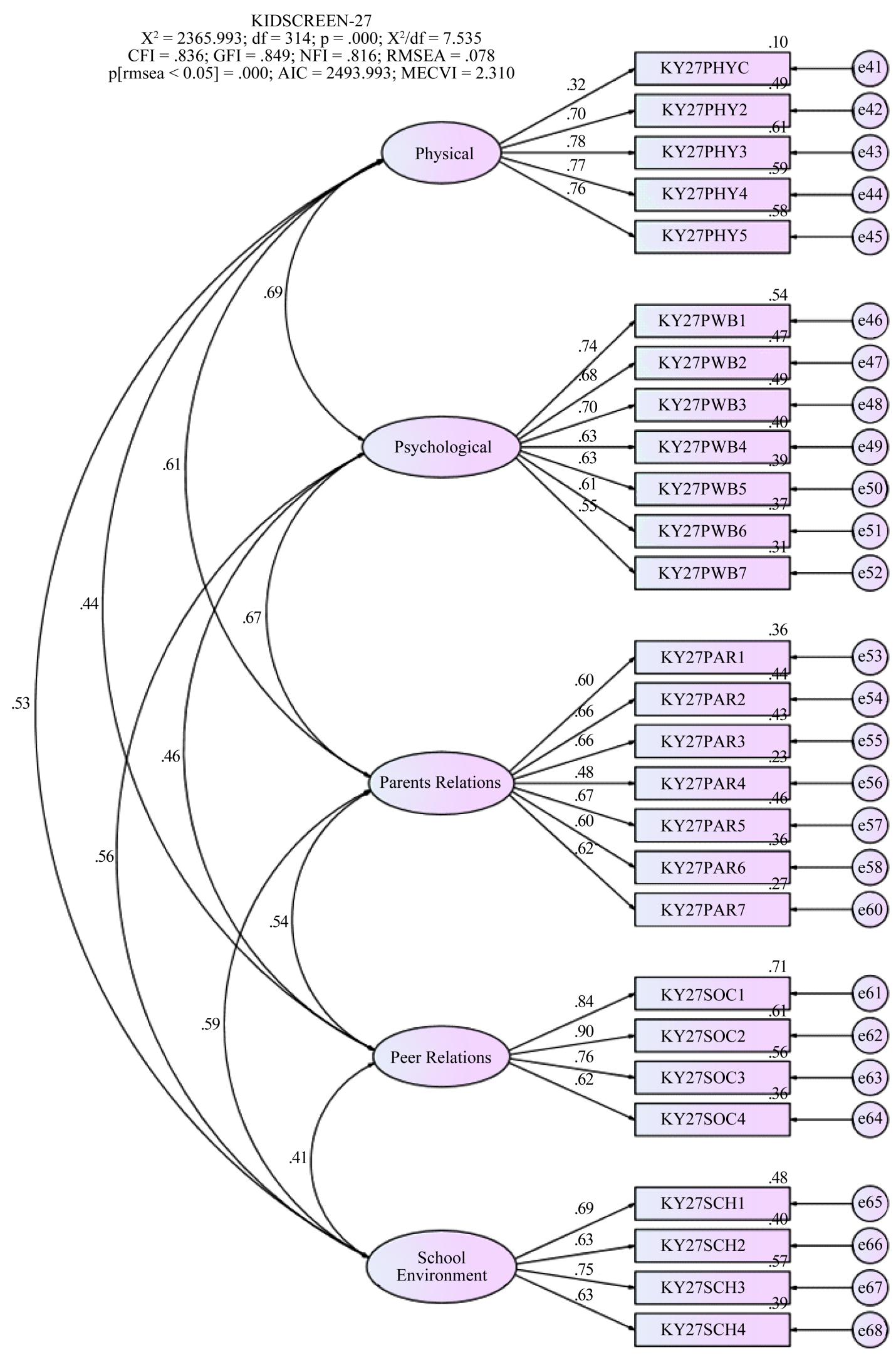

Figure 1. KIDSCREEN-27, original model. 


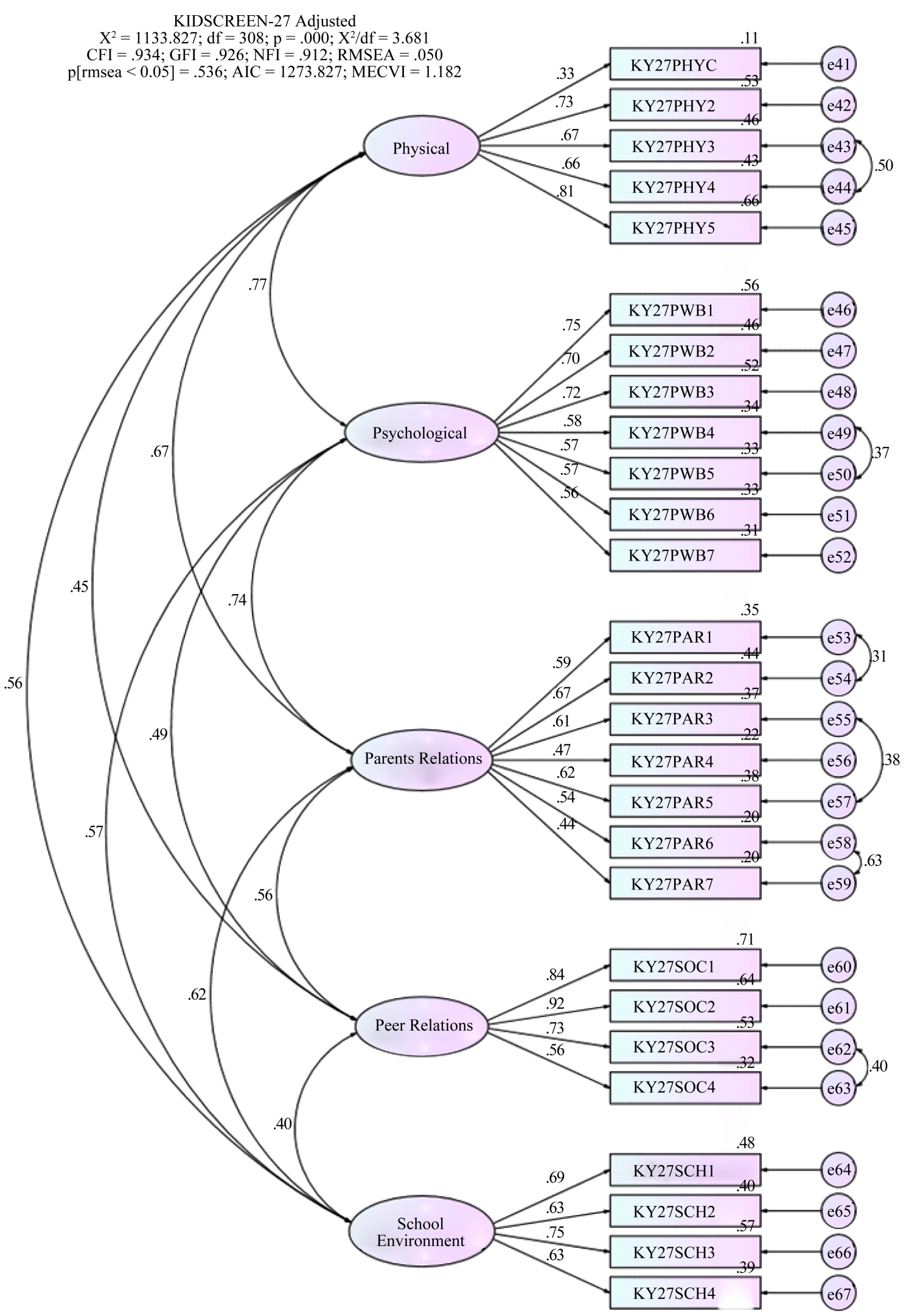

Figure 2. KIDSCREEN-27, adjusted model. 
Table 1. Reliability of KIDSCREEN-27 adjusted model.

\begin{tabular}{|c|c|c|c|c|c|c|}
\hline Dimension & Variable & $\begin{array}{c}\text { Factorial } \\
\text { weight }(\lambda)\end{array}$ & Sig. & $\begin{array}{c}\text { Composite } \\
\text { reliability (CR) }\end{array}$ & $\begin{array}{c}\text { Individual } \\
\text { reliability }\left(\lambda^{2}\right)\end{array}$ & $\begin{array}{l}\text { Average variance } \\
\text { extracted (AVE) }\end{array}$ \\
\hline \multirow{5}{*}{ Physical Well Being (PHY) } & KY27PHY1 & 0.388 & $<0.001$ & 0.792 & 0.151 & \multirow[t]{5}{*}{0.443} \\
\hline & KY27PHY2 & 0.733 & $<0.001$ & & 0.537 & \\
\hline & КY27PHY3 & 0.670 & $<0.001$ & & 0.449 & \\
\hline & KY27PHY4 & 0.658 & $<0.001$ & & 0.433 & \\
\hline & KY27PHY5 & 0.804 & $<0.001$ & & 0.646 & \\
\hline \multirow{7}{*}{ Psychological Well Being (PSY) } & KY27PWB1 & 0.746 & $<0.001$ & 0.827 & 0.557 & \multirow[t]{7}{*}{0.409} \\
\hline & KY27PWB2 & 0.696 & $<0.001$ & & 0.484 & \\
\hline & KY27PWB3 & 0.721 & $<0.001$ & & 0.52 & \\
\hline & KY27PWB4 & 0.580 & $<0.001$ & & 0.336 & \\
\hline & KY27PWB5 & 0.572 & $<0.001$ & & 0.327 & \\
\hline & KY27PWB6 & 0.571 & $<0.001$ & & 0.326 & \\
\hline & KY27PWB7 & 0.561 & $<0.001$ & & 0.315 & \\
\hline \multirow{7}{*}{ Autonomy Parental relation (PAR) } & KY27PAR1 & 0.589 & $<0.001$ & 0.765 & 0.347 & \multirow[t]{7}{*}{0.322} \\
\hline & KY27PAR2 & 0.666 & $<0.001$ & & 0.444 & \\
\hline & KY27PAR3 & 0.610 & $<0.001$ & & 0.372 & \\
\hline & KY27PAR4 & 0.474 & $<0.001$ & & 0.225 & \\
\hline & KY27PAR5 & 0.616 & $<0.001$ & & 0.379 & \\
\hline & KY27PAR6 & 0.536 & $<0.001$ & & 0.287 & \\
\hline & KY27PAR7 & 0.444 & $<0.001$ & & 0.197 & \\
\hline \multirow{4}{*}{ Social Support and Peers (SOC) } & KY27SOC1 & 0.843 & $<0.001$ & 0.853 & 0.711 & \multirow[t]{4}{*}{0.601} \\
\hline & KY27SOC2 & 0.919 & $<0.001$ & & 0.845 & \\
\hline & KY27SOC3 & 0.727 & $<0.001$ & & 0.529 & \\
\hline & KY27SOC4 & 0.565 & $<0.001$ & & 0.319 & \\
\hline \multirow{4}{*}{ School Environment (SCH) } & KY27SCH1 & 0.694 & $<0.001$ & 0.773 & 0.482 & \multirow[t]{4}{*}{0.461} \\
\hline & KY27SCH2 & 0.633 & $<0.001$ & & 0.401 & \\
\hline & KY27SCH3 & 0.755 & $<0.001$ & & 0.57 & \\
\hline & KY27SCH4 & 0.626 & $<0.001$ & & 0.392 & \\
\hline
\end{tabular}

Three types of validity determine construct validity: factorial validity, convergent validity and discriminant validity. As all items showed factorial weights greater than 0.5 (except for KY27PHY1, KY27PAR4 and KY27PAR7 items), it can be said that the scale has factorial validity as a whole.

Convergent validity was assessed by Average Variance Extracted (AVE) (Fornell \& Larcker, 1981). If AVE is greater than 0.50 , then the variance due to measurement error is fewer than the variance captured by the construct, by which it can be concluded that the measuring instrument presents convergent validity. As can be seen in Table 1, AVE is below 0.50 for four of five factors. Only Social Support \& Peers showed AVE greater than 0.5 and convergent validity is questionable. 
The discriminant validity can be evaluated by the average variance extracted test (Fornell \& Larcker, 1981). Therefore, if AVE is greater than the square of the correlation between latent variables (inter-factor correlations) then the instrument or model measure has discriminant validity. The analysis of these values (shown in the Table 2) allows us to state that Social Support \& Peers Relations (SOC) and School Environment (SCH) constructs discriminate all other factors scale, i.e., its AVE is greater than the square of the correlation that these factors establish with the other factors of the scale, the same is not true for the other factors which AVE were fewer than the square of the correlation inter-factor.

\subsection{Exploring FIT (Self-Concepts and Other's Concepts) Factorial Structure}

In the validation of the CFA assumptions, none of the variables showed skewness (Sk) and kurtosis $(K u)$ values as indicators of severe violations of the normal distribution ( $|\mathrm{Sk}|<3$ and $|\mathrm{Ku}|<7-10)$ (Marôco, 2014). The existence of outliers was evaluated by the Mahalanobis distance squared $\left(D^{2}\right)$ and several observations (100) were multivariate outliers. The analysis without these observations, did not produce significant improvements in the model, for this reason it was decided to keep all observations and make the model refinement only by analyzing the modification indices (MI). The original measurement model with all variables and all observations including outliers is in Figure $3\left(X^{2} / d f=5.965, G F I=0.716, C F I=0.728, N F I=0.691, R M S E A=0.068\right)$. As can be seen, the values of the adjustment quality indices are slightly apart from the values deemed acceptable $\left(X^{2} / d f<2, G F I>0.9, C F I>0.9, N F I>0.9\right.$, RMSEA $\left.<0.05\right)$ (Marôco, 2014).

Examining the regression weights and standardized regression weights obtained in the model, some items showed problems: several items showed very low factor weights (much less than 0.5) and were not statistically significant (Jk127_3, Jk127_6, Jk128_6, Jk129_6, Jk133_3, Jk133_6).

Even after successive refinements, the FIT model 1 (Figure 4) presented adjustment indices (AI) better than the original, but the adjustment remained only poorly $\left(X^{2} / d f=4.236, G F I=0.799, C F I=0.826, N F I=0.784\right.$, RMSEA = 0.055).

From these findings, it was proceeded to the removal of items not significant $(p>0.10)$ and items that were with very low factor weights (below 0.5). In summary, items 3, 6, and 9 of all factors were eliminated. The item 8 obtained appropriate factor weight in only two factors (ideal self-image and grandparent image) and was also cut off from all factors. There was, thus, obtained an alternative model (Figure 5). This model has an acceptable adjustment quality $\left(X^{2} / d f=4.352, G F I=0.861, C F I=0.902, N F I=0.877, R M S E A=0.056\right)$, with better indices than the previous models.

The reliability of the measurement model 2 was assessed by composite reliability. The results showed that all factors presented a high composite reliability, superior to 0.8 in every factor, so it can be concluded that taken together, the items are a reliable measure of the respective construct. Regarding to individual reliability of the items, it was assessed by the square of the standardized factorial weights $\left(\lambda^{2}\right)$. If these were greater than 0.25 it could be said that the items were individually reliable. As can be seen, all items had a higher value than 0.25 , so it can be concluded that all items showed individual reliability (Table 3).

Regarding the factorial validity it can be said that the measuring instrument has factorial validity since all its items showed factorial weights higher than 0.5 . The convergent validity of each factor was evaluated by the Average Variance Extracted (AVE). As can be seen, all factors, except the Real Self-image factor, exhibited AVE values above 0.5 (Table 3 ).

Table 2. AVE comparisons with the squared inter-factor correlations of KIDSCREEN-27 adjusted model.

\begin{tabular}{|c|c|c|c|c|c|c|}
\hline \multirow{2}{*}{ Dimensions } & \multicolumn{5}{|c|}{ Squared inter-Factor Correlation } & \multirow{2}{*}{ AVE } \\
\hline & PHY & PSY & PAR & SOC & $\mathrm{SCH}$ & \\
\hline Physical Wellbeing (PHY) & & 0.593 & 0.448 & 0.203 & 0.316 & 0.443 \\
\hline Psychological Wellbeing (PSY) & 0.593 & & 0.545 & 0.235 & 0.327 & 0.409 \\
\hline Autonomy \& Relationships with Parents (PAR) & 0.448 & 0.545 & & 0.316 & 0.387 & 0.322 \\
\hline Social Support \& Peer Relations (SOC) & 0.203 & 0.235 & 0.316 & & 0.162 & 0.601 \\
\hline School Environment (SCH) & 0.316 & 0.327 & 0.387 & 0.162 & & 0.461 \\
\hline
\end{tabular}


FIT (Self-images \& Other's image) Original Model $\mathrm{X}^{2}=10140.000 ; \mathrm{df}=1700 ; \mathrm{p}=.000 ; \mathrm{X}^{2} / \mathrm{df}=5.965$

$\mathrm{CFI}=.728 ; \mathrm{GFI}=.716 ; \mathrm{NFI}=.691 ; \mathrm{RMSEA}=.068$ $\mathrm{p}[\mathrm{rmsea}<0.05]=.000$

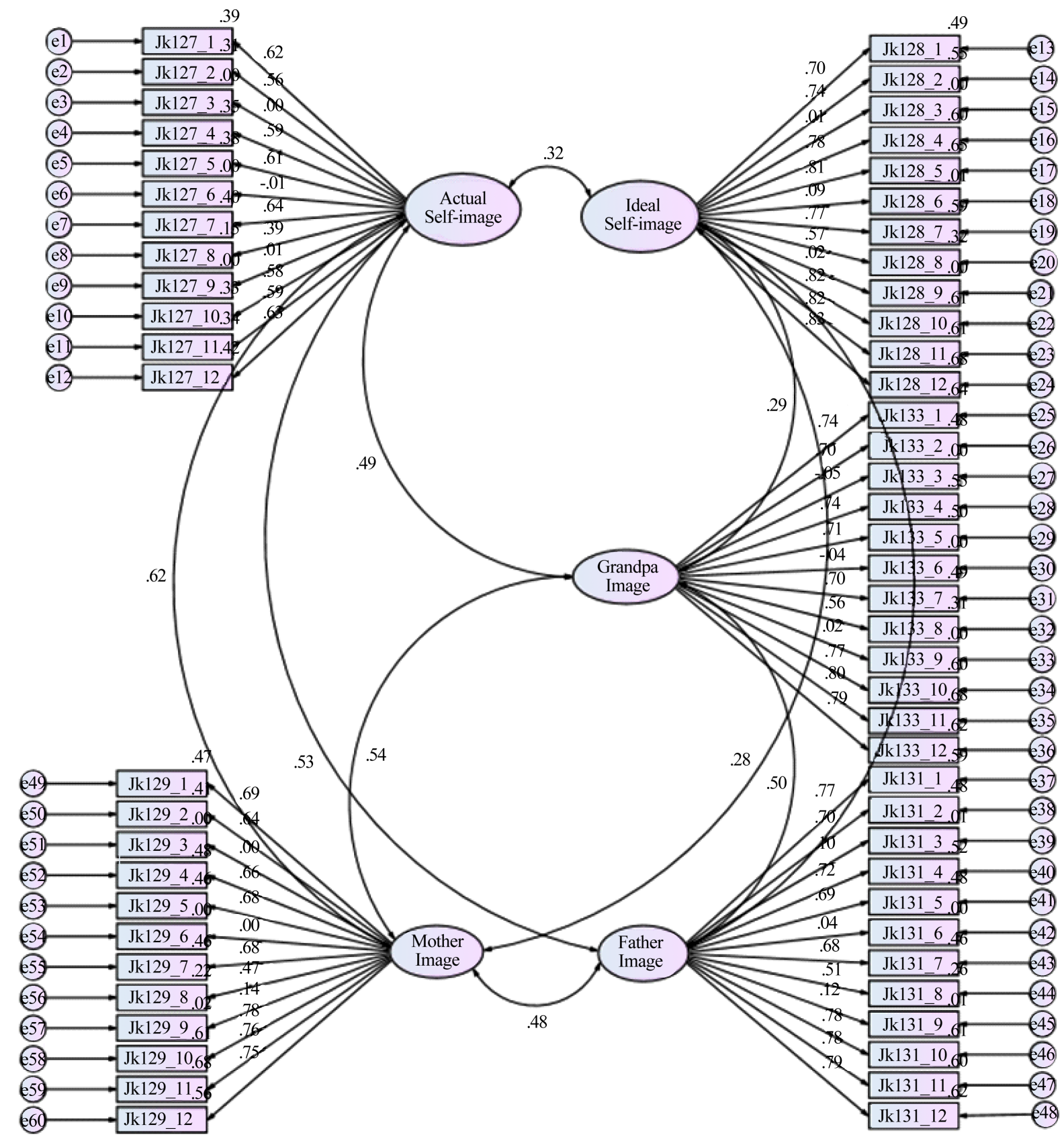

Figure 3. FIT (Self-images and Other's image), original model.

To assess the discriminant validity, it was proceeded to compare the AVE values of each factor with the squared inter-factor correlation (Table 4). As can be seen, all factors, except the factors Real Self-image and Mother Image, discriminate each other.

This model has acceptable psychometric qualities: has factorial validity, convergent validity was not obtained for the Real Self-image factor only, and discriminant validity just does not happen between two factors. Moreover, it presents reliability as a whole, as well as individual reliability. 


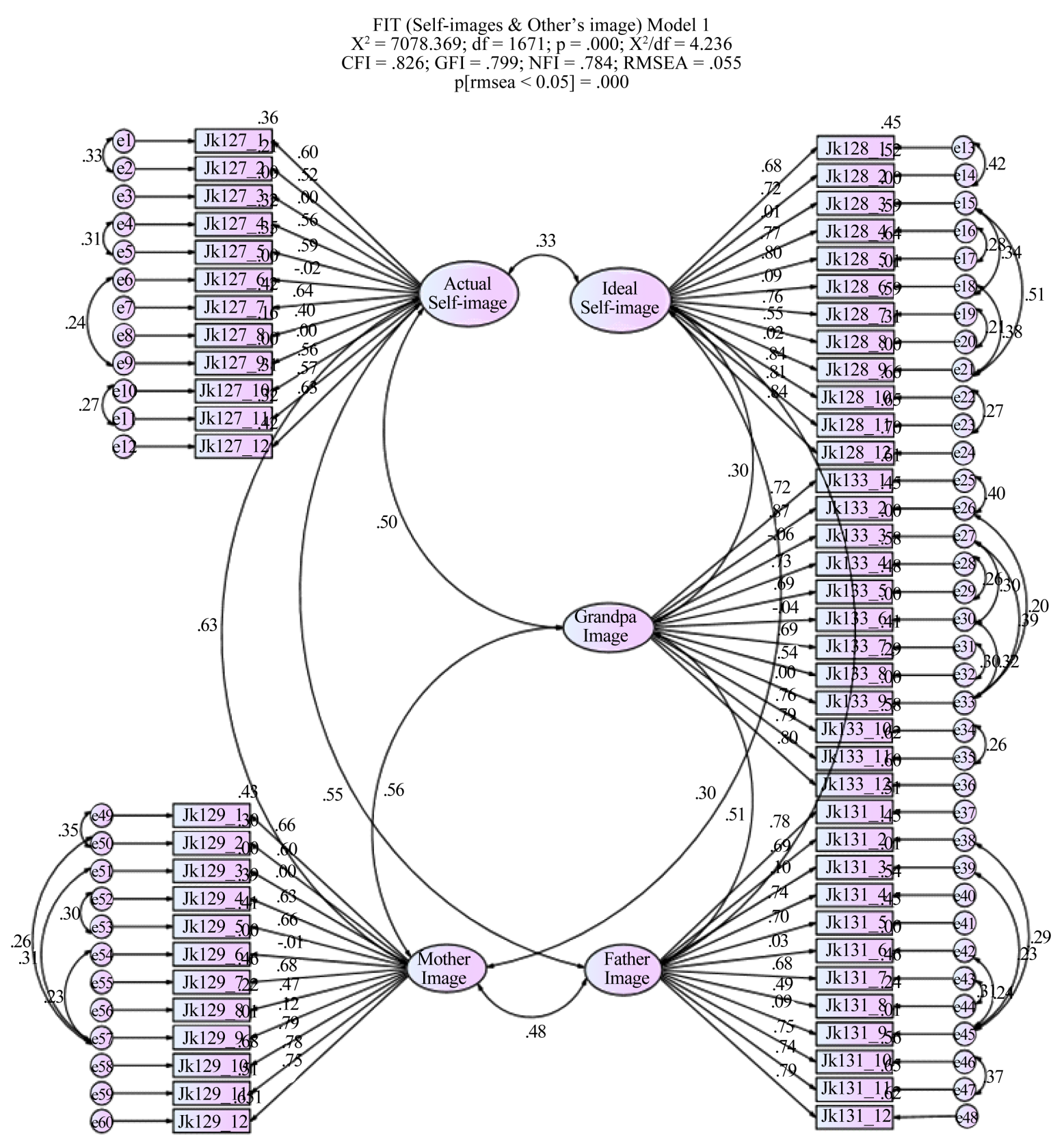

Figure 4. FIT (Self-images and other’s image), model 1.

\subsection{The Structural Model: FIT (Self-Concepts \& Other's Concepts) versus KIDSCREEN-27}

After obtaining the adjusted models of the two constructs target, it was drawn a structural model through the Causal Model with Latent Variables (CMLV) as described in Marôco (Marôco, 2014). The factor structure of both target models had already been properly validated, as previously reported. The factors obtained with the FIT were considered as the predictor variables and from each one, paths were drawn to obtain the causal trajectories. After the estimation by maximum likelihood method implemented with IBMCAMOS, the significance of the regression coefficients were evaluated and, for parsimony reasons, all non-significant trajectories were removed from the model. The structural model adjusted is on Figure 6.

The trajectories of the model with their non-standardized partial regression coefficients $(B)$ with p-values, standardized errors (SE) and the standardized partial regression coefficients $(\beta)$ are on Table 5. 
FIT (Self-images \& Other's image) Model 2

$\mathrm{X}^{2}=3128.862 ; \mathrm{df}=719 ; \mathrm{p}=.000 ; \mathrm{X}^{2} / \mathrm{df}=4.352$

$\mathrm{CFI}=.902 ; \mathrm{GFI}=.861 ; \mathrm{NFI}=.877 ; \mathrm{RMSEA}=.056$ $\mathrm{p}[\mathrm{rmsea}<0.05]=.000$

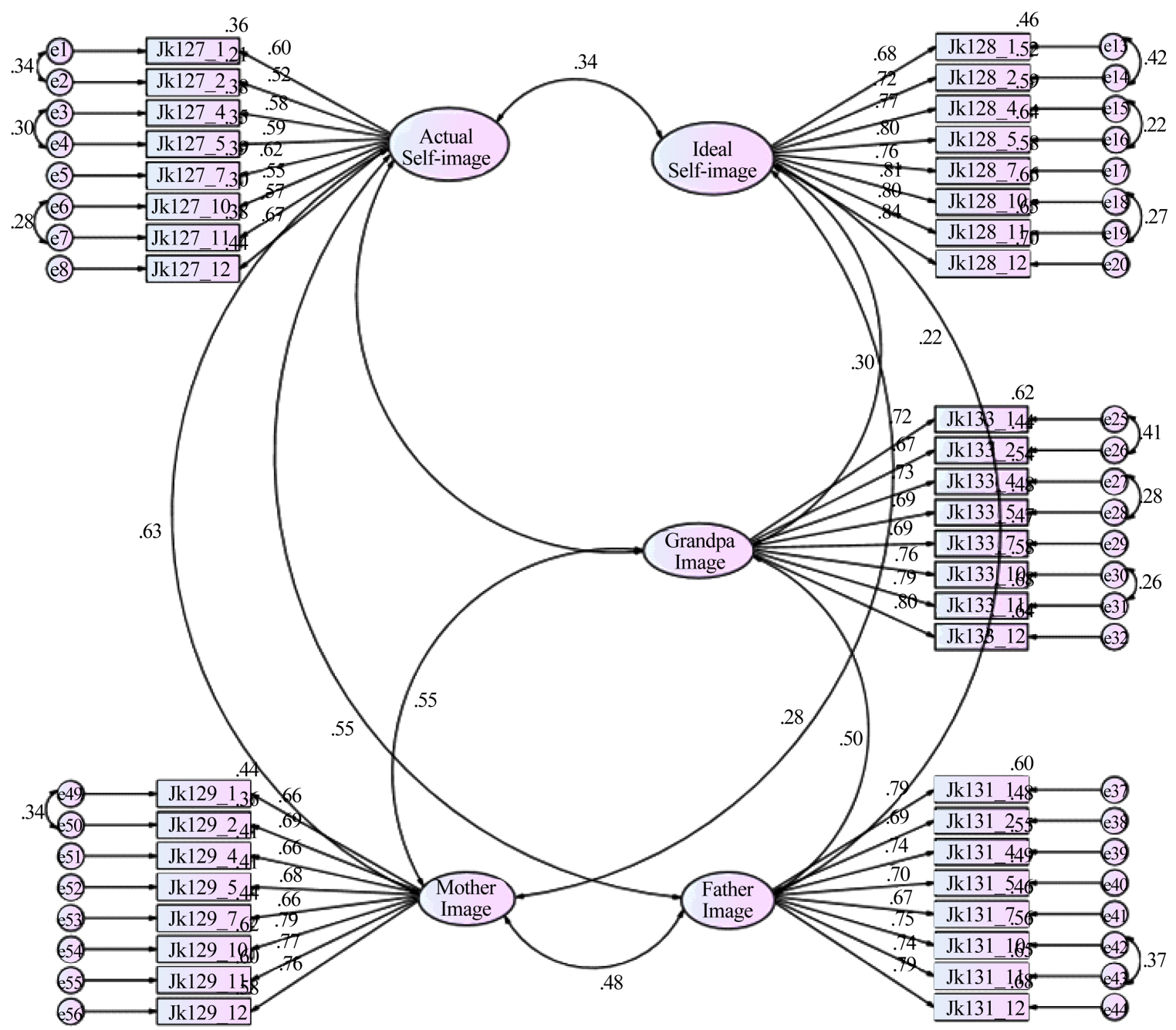

Figure 5. FIT (Self-images and Other's image), model 2.

As can be seen, the Structural Model has a reasonably good quality $\left(X^{2} / d f=2.853, G F I=0.847, C F I=0.899\right.$, $N F I=0.853, R M S E A=0.041, p=1$ ). The trajectories analysis of the factors show that: the Actual Self-image shows a statistically significant and positive impact on all factors that comprise the KIDSCREEN-27 questionnaire and has greater impact on Physical Wellbeing $(B=0.789, S E=0.06, \beta=0.630, p<0.001)$ and Psychological Wellbeing $(B=0.734, S E=0.053, \beta=0.636, p<0.001)$ factors and a lower impact on Autonomy \& Relationships with Parents $(B=0.228, S E=0.049, \beta=0252, p<0.001)$ factor; the Ideal Self-image presents a statistically significant and negative impact on only three of five factors of KIDSCREEN-27, Physical Wellbeing ( $B$ $=-0.110, S E=0.033, \beta=-0108, p=0.001)$, Psychological Wellbeing $(B=-0.085, S E=0.029, \beta=-0090, p=$ 0.003) and Autonomy \& Relationships with Parents $(B=-0.062, S E=0.023, \beta=-0083, p=0.007)$; the Mother Image has statistically significant and positive impact only on Autonomy \& Relationships with Parents $(B=$ $0.246, S E=0.038, \beta=0.292, p<0.001$ ) factor; the Father Image as the Mother Image has a positive and statistically significant impact on Autonomy \& Relationships with Parents $(B=0.157, S E=0.026, \beta=0.235, p<$ 0.001 ) factor and also features a statistically significant and positive impact, although with much less weight on the School Environment factor $(B=0.076, S E=0.034, \beta=0.094, p=0.023)$; the Grandparent Image as the Father Image has a positive and statistically significant impact on Autonomy \& Relationships with Parents $(B=$ 
Table 3. Reliability of FIT (Self-images and other’s image) adjusted model.

\begin{tabular}{|c|c|c|c|c|c|c|}
\hline Factor & Item & Factorial weight $(\lambda)$ & Sig. & Composite reliability & Individual reliability $\left(\lambda^{2}\right)$ & AVE \\
\hline \multirow{8}{*}{ Real Self-image } & Jk127_1 & 0.599 & $<0.001$ & \multirow[t]{8}{*}{0.808} & 0.359 & \multirow[t]{8}{*}{0.349} \\
\hline & Jk127_2 & 0.522 & $<0.001$ & & 0.272 & \\
\hline & Jk127_4 & 0.577 & $<0.001$ & & 0.333 & \\
\hline & Jk127_5 & 0.591 & $<0.001$ & & 0.349 & \\
\hline & Jk127_7 & 0.622 & $<0.001$ & & 0.387 & \\
\hline & Jk127_10 & 0.549 & $<0.001$ & & 0.301 & \\
\hline & Jk127_11 & 0.571 & $<0.001$ & & 0.326 & \\
\hline & Jk127_12 & 0.666 & $<0.001$ & & 0.444 & \\
\hline \multirow{8}{*}{ Ideal Self-image } & Jk128_1 & 0.679 & $<0.001$ & \multirow[t]{8}{*}{0.923} & 0.461 & \multirow[t]{8}{*}{0.600} \\
\hline & Jk128_2 & 0.722 & $<0.001$ & & 0.521 & \\
\hline & Jk128_4 & 0.768 & $<0.001$ & & 0.590 & \\
\hline & Jk128_5 & 0.798 & $<0.001$ & & 0.637 & \\
\hline & Jk128_7 & 0.764 & $<0.001$ & & 0.584 & \\
\hline & Jk128_10 & 0.811 & $<0.001$ & & 0.658 & \\
\hline & Jk128_11 & 0.804 & $<0.001$ & & 0.646 & \\
\hline & Jk128_12 & 0.838 & $<0.001$ & & 0.702 & \\
\hline \multirow{8}{*}{ Mother image } & Jk129_1 & 0.661 & $<0.001$ & \multirow[t]{8}{*}{0.885} & 0.437 & \multirow[t]{8}{*}{0.493} \\
\hline & Jk129_2 & 0.604 & $<0.001$ & & 0.365 & \\
\hline & Jk129_4 & 0.661 & $<0.001$ & & 0.437 & \\
\hline & Jk129_5 & 0.684 & $<0.001$ & & 0.468 & \\
\hline & Jk129_7 & 0.663 & $<0.001$ & & 0.440 & \\
\hline & Jk129_10 & 0.787 & $<0.001$ & & 0.619 & \\
\hline & Jk129_11 & 0.773 & $<0.001$ & & 0.598 & \\
\hline & Jk129_12 & 0.762 & $<0.001$ & & 0.581 & \\
\hline \multirow{8}{*}{ Father image } & Jk131_1 & 0.776 & $<0.001$ & \multirow[t]{8}{*}{0.904} & 0.602 & \multirow[t]{8}{*}{0.540} \\
\hline & Jk131_2 & 0.695 & $<0.001$ & & 0.483 & \\
\hline & Jk131_4 & 0.741 & $<0.001$ & & 0.549 & \\
\hline & Jk131_5 & 0.702 & $<0.001$ & & 0.493 & \\
\hline & Jk131_7 & 0.675 & $<0.001$ & & 0.456 & \\
\hline & Jk131_10 & 0.748 & $<0.001$ & & 0.560 & \\
\hline & Jk131_11 & 0.744 & $<0.001$ & & 0.554 & \\
\hline & Jk131_12 & 0.792 & $<0.001$ & & 0.627 & \\
\hline \multirow{8}{*}{ Grandparent image } & Jk133_1 & 0.719 & $<0.001$ & \multirow[t]{8}{*}{0.902} & 0.517 & \multirow[t]{8}{*}{0.537} \\
\hline & Jk133_2 & 0.665 & $<0.001$ & & 0.442 & \\
\hline & Jk133_4 & 0.732 & $<0.001$ & & 0.536 & \\
\hline & Jk133_5 & 0.691 & $<0.001$ & & 0.477 & \\
\hline & Jk133_7 & 0.689 & $<0.001$ & & 0.475 & \\
\hline & Jk133_10 & 0.759 & $<0.001$ & & 0.576 & \\
\hline & Jk133_11 & 0.791 & $<0.001$ & & 0.626 & \\
\hline & Jk133_12 & 0.803 & $<0.001$ & & 0.645 & \\
\hline
\end{tabular}

Table 4. AVE comparisons with the squared inter-factor correlations of FIT (Self-image and other's image) adjusted model.

\begin{tabular}{|c|c|c|c|c|c|c|}
\hline \multirow{2}{*}{ FIT (Self-images \& Other’s image } & \multicolumn{5}{|c|}{ Squared inter-factor correlation } & \multirow{2}{*}{ AVE } \\
\hline & RSI & ISI & MI & FI & GI & \\
\hline Real self-image (RSI) & & 0.112 & 0.401 & 0.303 & 0.256 & 0.349 \\
\hline Ideal self-image (ISI) & 0.112 & & 0.081 & 0.047 & 0.089 & 0.600 \\
\hline Mother image (MI) & 0.401 & 0.081 & & 0.225 & 0.307 & 0.493 \\
\hline Father image (FI) & 0.303 & 0.047 & 0.225 & & 0.252 & 0.540 \\
\hline Grandparent image (GI) & 0.256 & 0.089 & 0.307 & 0.252 & & 0.537 \\
\hline
\end{tabular}




\section{Structural Model}

$\mathrm{X}^{2}=5968.707 ; \mathrm{df}=2092 ; \mathrm{p}=.000 ; \mathrm{X}^{2} / \mathrm{df}=2.853$

$\mathrm{CFI}=.899 ; \mathrm{GFI}=.847 ; \mathrm{NFI}=.853 ; \mathrm{RMSEA}=.041$

$\mathrm{p}[\mathrm{rmsea}<0.05]=1.000 ; \mathrm{AIC}=6340.707 ; \mathrm{MECVI}=5.889$

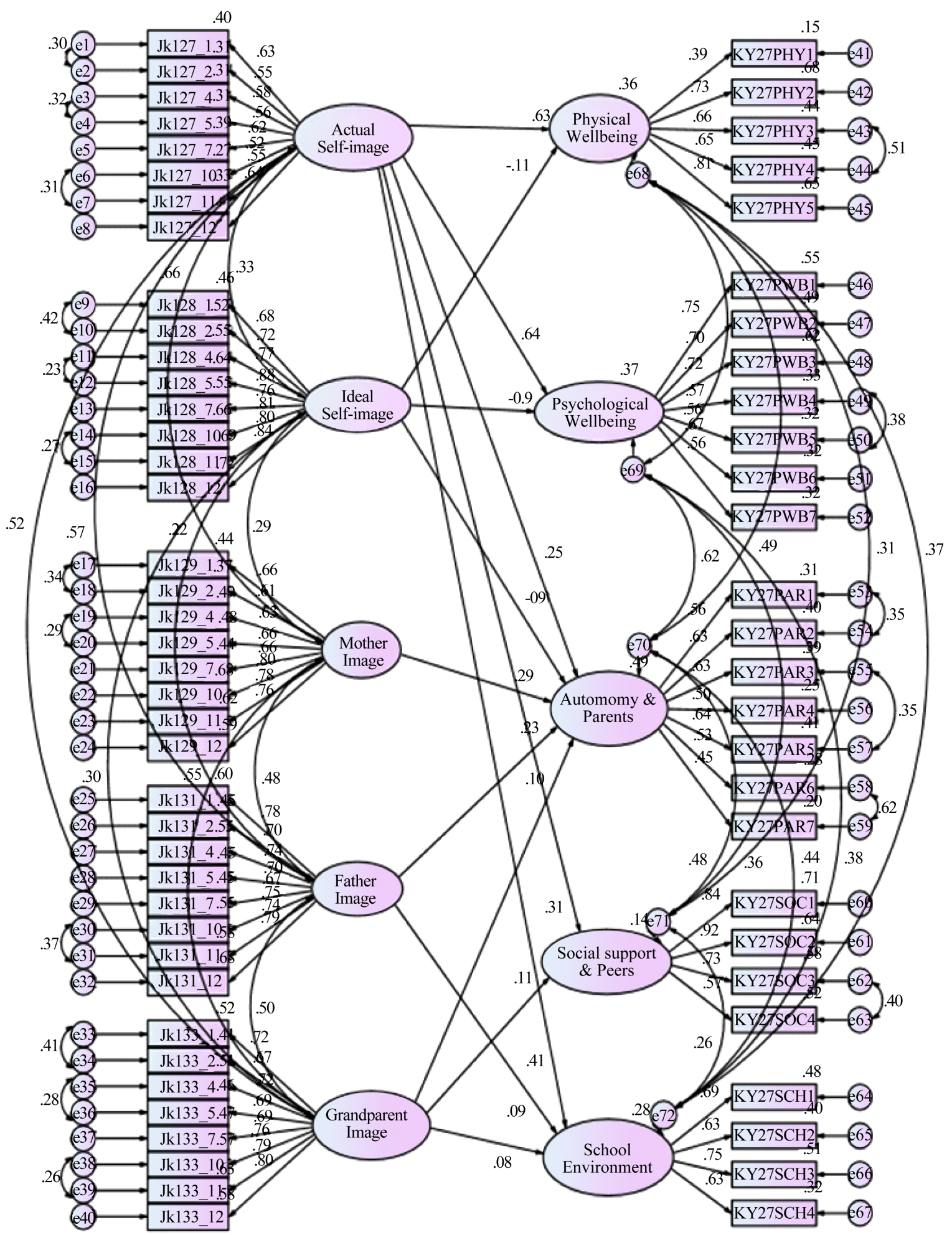

Figure 6. Structural model. 
Table 5. Trajectories of structural model.

\begin{tabular}{|c|c|c|c|c|}
\hline \multirow{2}{*}{ Trajectory } & \multirow{2}{*}{$B$} & \multirow{2}{*}{$S E$} & \multirow{2}{*}{$\beta$} & Sig. \\
\hline & & & & (p-value) \\
\hline Actual Self-image $\leftrightarrow$ Physical Wellbeing & 0.789 & 0.060 & 0.630 & $<0.001$ \\
\hline Actual Self-image $\leftrightarrow$ Psychological Wellbeing & 0.734 & 0.053 & 0.636 & $<0.001$ \\
\hline Actual Self-image $\leftrightarrow$ Autonomy \& Relationships with Parents & 0.228 & 0.049 & 0.252 & $<0.001$ \\
\hline Actual Self-image $\leftrightarrow$ Social support \& Peers relations & 0.397 & 0.056 & 0.306 & $<0.001$ \\
\hline Actual Self-image $\leftrightarrow$ School Environment & 0.453 & 0.057 & 0.414 & $<0.001$ \\
\hline Ideal Self-image $\leftrightarrow$ Physical Wellbeing & -0.110 & 0.033 & -0.108 & $<0.001$ \\
\hline Ideal Self-image $\leftrightarrow$ Psychological Wellbeing & -0.085 & 0.029 & -0.090 & 0.003 \\
\hline Ideal Self-image $\leftrightarrow$ Autonomy \& Relationships with Parents & -0.062 & 0.023 & -0.083 & 0.007 \\
\hline Mother Image $\leftrightarrow$ Autonomy \& Relationships with Parents & 0.246 & 0.038 & 0.292 & $<0.001$ \\
\hline Father Image $\leftrightarrow$ Autonomy \& Relationships with Parents & 0.157 & 0.026 & 0.235 & $<0.001$ \\
\hline Father Image $\leftrightarrow$ School Environment & 0.076 & 0.034 & 0.094 & 0.023 \\
\hline Grandparent Image $\leftrightarrow$ Autonomy \& Relationships with Parents & 0.074 & 0.029 & 0.098 & 0.012 \\
\hline Grandparent Image $\leftrightarrow$ Social support \& Peers relations & 0.119 & 0.041 & 0.109 & 0.004 \\
\hline Grandparent Image $\leftrightarrow$ School Environment & 0.076 & 0.037 & 0.083 & 0.037 \\
\hline
\end{tabular}

0.074, $S E=0.029, \beta=0.098, p=0.012)$ and School Environment $(B=0.076, S E=0.037, \beta=0.084, p=0.037)$ factors, although with a lower weight. However, it is in the KIDSCREEN-27 factor of Social Support \& Peers Relations that the impact of Grandparent Image has the greatest effect $(B=0.119, S E=0.041, \beta=0.109, p=$ 0.004).

The standardized total effects from self-concepts measured with FIT on KIDSCREEN-27 (dimensions and subscales) by Structural Model are on Table 6. Regarding the effects of Actual Self-image on Physical Wellbeing, the items with higher contribution were items 5 (KY27PHY5) "Have you felt full of energy?” and 2 (KY27PHY2) “Have you felt physically fit and well?”. Regarding the effects of Actual Self-image on Psychological Wellbeing, the items with the highest contribution were items 1 (KY27PSY1) "Has your life been enjoyable?” and 3 (KY27PSY3) "Have you had fun?”.

Regarding the effects of perceived Image of the Mother on Autonomy \& Relationships with Parents, there was a balance between the seven items of the KIDSCREEN-27 subscale with the greatest contribution of item 5 (KY27PAR5) “Have you been able talk to your parent(s) when you wanted to?”. Regarding the effects of perceived Image of the Father on Autonomy \& Relationships with Parents, the same trend found with mother continued and, on the dimension School Environment, the greatest contribution was from subscale 3 (KY27SCH3) "Have you been able to pay attention?”.

Regarding the effects of perceived Image of the Grandparent it was found a weak predictive power in three dimensions of KIDSCREEN-27, Social Support and Peer Relations (SOC), Autonomy \& Relationships with Parents (PAR) and School Environment (SCH). On the first one, the greatest contribution was from item 2 (KY27SOC2) "Have you had fun with your friends?; on the second, the greatest contribution was from item 5 (KY27PAR5) similar to parents and for the last, the greatest contribution was from item 3 (KY27SCH3) "Have you been able to pay attention?”.

\section{Discussion and Conclusion}

The present study aimed to evaluate the impact of self-concepts and the concepts of significant others measured with the FIT in the HRQoL, measured with the generic questionnaire KIDSCREEN-27. It was hypothesized that there were relations between those cognitive representations of self with HRQoL dimensions similarly to what has been found by other researchers regarding to the wellbeing. 
Table 6. Standardized total effects from FIT self-concepts on KIDSCREEN-27 (Dimensions and subscales).

\begin{tabular}{|c|c|c|c|c|c|}
\hline & $\begin{array}{l}\text { Actual } \\
\text { self-image }\end{array}$ & $\begin{array}{l}\text { Ideal } \\
\text { self-image }\end{array}$ & $\begin{array}{l}\text { Mother } \\
\text { image }\end{array}$ & $\begin{array}{l}\text { Father } \\
\text { image }\end{array}$ & $\begin{array}{l}\text { Grandparen } \\
\text { image }\end{array}$ \\
\hline Physical Wellbeing (PHY) & 0.630 & -0.108 & & & \\
\hline Psychological Wellbeing (PSY) & 0.636 & -0.090 & & & \\
\hline Autonomy \& Relationships with Parents (PAR) & 0.252 & -0.083 & 0.292 & 0.235 & 0.098 \\
\hline Social Support \& Peers relations (SOC) & 0.306 & & & & 0.109 \\
\hline School Environment (SCH) & 0.414 & & & 0.094 & 0.083 \\
\hline KY27PHY1 In general, how would you say your health is? & 0.246 & -0.042 & & & \\
\hline KY27PHY2 Have you physically felt fit and well? & 0.460 & -0.079 & & & \\
\hline KY27PHY3 Have you been physically active ? & 0.419 & -0.072 & & & \\
\hline KY27PHY4 Have you been able to run well? & 0.413 & -0.071 & & & \\
\hline KY27PHY5 Have you felt full of energy? & 0.510 & -0.087 & & & \\
\hline KY27PWB1 Has your life been enjoyable? & 0.476 & -0.068 & & & \\
\hline KY27PWB2 Have you been in a good mood? & 0.447 & -0.064 & & & \\
\hline KY27PWB3 Have you had fun? & 0.458 & -0.065 & & & \\
\hline KY27PWB4 Have you felt sad? & 0.364 & -0.052 & & & \\
\hline $\begin{array}{l}\text { KY27PWB5 Have you felt so bad that you didn't want } \\
\text { to do anything? }\end{array}$ & 0.359 & -0.051 & & & \\
\hline KY27PWB6 Have you felt lonely? & 0.360 & -0.051 & & & \\
\hline KY27PWB7 Have you been happy with the way you are? & 0.357 & -0.051 & & & \\
\hline KY27PAR1 Have you had enough time for yourself? & 0.141 & -0.047 & 0.163 & 0.131 & 0.055 \\
\hline $\begin{array}{l}\text { KY27PAR2 Have you been able to do the things that } \\
\text { you want to do in your free time? }\end{array}$ & 0.159 & -0.052 & 0.184 & 0.148 & 0.061 \\
\hline KY27PAR3 Have your parent(s) had enough time for you? & 0.158 & -0.052 & 0.184 & 0.148 & 0.061 \\
\hline KY27PAR4 Have your parent(s) treated you fairly? & 0.126 & -0.042 & 0.146 & 0.117 & 0.049 \\
\hline $\begin{array}{l}\text { KY27PAR5 Have you been able talk to your parent(s) } \\
\text { when you wanted to? }\end{array}$ & 0.160 & -0.053 & 0.186 & 0.150 & 0.062 \\
\hline $\begin{array}{l}\text { KY27PAR6 Have you had enough money to do the } \\
\text { same things as your friends? }\end{array}$ & 0.134 & -0.044 & 0.155 & 0.125 & 0.052 \\
\hline KY27PAR7 Have you had enough money for your expenses? & 0.114 & -0.038 & 0.132 & 0.106 & 0.044 \\
\hline KY27SOC1 Have you spent time with your friends? & 0.258 & & & & 0.092 \\
\hline KY27SOC2 Have you had fun with your friends? & 0.280 & & & & 0.100 \\
\hline KY27SOC3 Have you and your friends helped each other? & 0.222 & & & & 0.079 \\
\hline KY27SOC4 Have you been able to rely on your friends? & 0.173 & & & & 0.062 \\
\hline KY27SCH1 Have you been happy at school? & 0.286 & & & 0.065 & 0.058 \\
\hline KY27SCH2 Have you got on well at school? & 0.261 & & & 0.060 & 0.053 \\
\hline KY27SCH3 Have you been able to pay attention? & 0.312 & & & 0.071 & 0.063 \\
\hline KY27SCH4 Have you got along well with your teachers? & 0.260 & & & 0.059 & 0.052 \\
\hline
\end{tabular}


In the construction of the structural model covering the two constructs, it was necessary to evaluate the factorial structure of both instruments. Regarding the factorial structure of the KIDSCREEN-27 questionnaire, the validity of a five-factor model was evident, but it was necessary to fit the model through the modification indices with the correlation between seven pairs of variables errors over four of the five factors. The model, as a whole, achieved factorial validity. However, the convergent and discriminant validity were not achieved at all factors. Regarding the factor structure of FIT, the original factorial structure did not show acceptable quality indicators and their analysis showed multiple items with factorial weights very low and/or negative, particularly items 3, 6, 8 and 9 that correspond to the adjectives, anxious, moody, independent and nervous, respectively. The adjectives anxious, moody and nervous corresponding to neuroticism factor (the first, with negative polarity and the last two with positive polarity) and the adjective independent corresponding to extraversion factor (assertiveness). As the FIT aims to cover three of the five major personality factors (Agreeableness, Extraversion and Neuroticism), it was found that with the removal of the problematic items would remain: two adjectives linked to negative polarity of neuroticism (content and calm); three linked to positive polarity of extraversion (active, talkative and self-confident) and three linked to agreeableness (understanding, considerate and friendly) that showed no problems. As the descriptors would be reduced from 12 to eight without losing the original test coverage was proceeded CFA, which after adjustments showed high composite reliability and individually reliability of the items.

In this analysis, in spite that the aim was not to investigate the concept of discrepancy between the actual self and the ideal self, the fact that two descriptors (adjectives) of the FIT that measure neuroticism have obtained very low and/or negative factor weights and thus were removed from the scale shows compatibility with Lynch et al. study (Lynch et al., 2009) who used the Big Factor Model to assess the self-concept in cross-cultural study with college students and found that young people had a tendency not to think of themselves as neurotic. Here this trait also, was partially rejected. It is possible that the translations of the FIT for the Brazilian Portuguese (Käppler, 2004; Teodoro, 2000) do not reflect exactly the current meaning of those descriptors in the original language (German) in which the FIT was created (Remschmidt \& Mattejat, 1999). Further cross-cultural studies are needed to analyze this aspect better.

After the factorial analysis of the instruments and the necessary adjustments, it was sought to outline a structural model to answer the main question: if the cognitive representations of self and significant others concepts may predict HRQoL in adolescents from different backgrounds. It was found evidence of that Actual Self-image can predict each of the dimensions of HRQoL measured by the KIDSCREEN-27, especially in the dimensions Physical Wellbeing and Psychological Wellbeing. The mother's perceived image is able to predict HRQoL only in dimension Autonomy \& Relationships with Parents; the father's perceived image in the dimensions Autonomy \& Relationships with Parents and School Environment and the perceived image of the significant grandparent predict HRQoL especially in dimension Social Support \& Peer Relations. The Ideal Self-image showed a weak negative predictive potential on three of five dependent variables (Physical Wellbeing, Psychological Wellbeing and Autonomy \& Relationships with Parents), meaning that, for every increase in the $\beta$ coefficient of the predictor variable, there is a reduction in the $\beta$ coefficient of the KIDSCREEN-27 dependent variable. It can be considered that, in terms of HRQoL of the adolescents under review, it is more important the perception of "how I am" and not "how I want to be".

When observing the effects of self-concepts and concepts of significant others on KIDSCREEN-27 subscales, some aspects are highlighted. The main effects of Actual Self-image on Physical Wellbeing subscales stressed the importance of leisure and physical activity. The effects of perceived Image of the Mother and Father on Autonomy \& Relationships with Parents subscales stressed the quality of interactions between adolescents and their parents. The effects of perceived Image of the Father on the dimension School Environment, stressed the perception of the adolescents about their cognitive ability, learning and concentration. Surprisingly the perceived images of the father and mother did not show predictive power in the other dimensions of HRQoL measured by KIDSCREEN-27. Finally with respect to the perceived Image of the Grandparent, the predictive effects were more weak than that of the parents images but their contribution was more extensive, which may indicate for a possible role of replacing or of complementing, which these parental figures represent for health and wellbeing of these adolescents, particularly on Social Support \& Peer Relations.

The structural model obtained as a whole sheds light on the role of Actual Self-image regarding the dimensionalities of HRQoL in adolescents measured from personality traits and confirmed that there are relations between the self-concepts and the significant others concepts with health-related quality of life as other authors 
(Beasley \& Garn, 2013; Fonseca, 2013; Barnett \& Hunter, 2012; Martinez, Martin, \& Dowson, 2006) have reported using different methodologies. Specifically, the study, which analyzed the adjustment of siblings of children with mental health problems, pointed out that several domains of self-concept were important predictors of behavior scores, but despite QoL be significantly lower in the group of siblings, this was not a significant predictor variable in the behavioral scores (Barnett \& Hunter, 2012) and similarly, the current study also concluded that the domains of QoL may be affected by self-concepts and not the opposite. The self-concepts, especially the actual self, proved that may predict all dimensions of HRQoL.

The findings cannot be generalized because of the characteristics of the sample but the results bring additions in this field and further studies are required to confirm the findings, especially cross-cultural studies.

\section{Acknowledgements}

We thank Professor Deise Matos do Amparo, PhD, from National University of Brasilia, Brazilian Coordinator of the multicenter project "Public health services: concepts of mental health and perceptions of the service from the perspective of adolescents and their families” and Coordinator of the research team in the city of Brasilia.

We thank Professor Júlia Bucher-Maluschke, PhD from Catholic University of Brasilia, Coordinator of the research team in the city of Fortaleza.

We thank Professor Silvia Helena Koller, PhD from Federal University of Rio Grande do Sul, Coordinator of the research team in the city of Porto Alegre.

We thank Professor Christoph Käppler, PhD from Technical University of Dortmund, International consultant of the Brazilian multicenter project "Public health services: concepts of mental health and perceptions of the service from the perspective of adolescents and their families".

We thank Psychologist Camila de Aquino Morais, PhD who during her Masters in Psychology at Federal University of Rio Grande do Sul, Brazil organized the national database and performed the data collection in the city of Porto Alegre.

We thank to Foundation for Research Support of the Federal District for financial assistance for the development of the research project "Public health services: concepts of mental health from the perspective of young people and their families" that contributed to the construction of a national database.

We thank to National Council for Scientific and Technological Development for financial assistance for the development of the research project "Conceptions and perceptions of mental health services from the perspective of youth and family" that contributed to the construction of a national database.

\section{References}

Aarstad, A. K. H., Aarstad, H. J., \& Olofsson, J. (2008). Personality and Choice of Coping Predict Quality of Life in Head and Neck Cancer Patients during Follow-Up. Acta Oncologica, 47, 879-890. http://dx.doi.org/10.1080/02841860701798858

Amparo, D. M., Brasil, K., Fukuda, C. C., Morais, C. A., Antunes, C., Penso, M. A. et al. (2010). Concepções de saúde e doença mental na perspectiva de jovens e seus cuidadores. Brasília, DF: Universidade Católica de Brasília/Universidade de Brasília.

Barnett, R., \& Hunter, M. (2012). Adjustment of Siblings of Children with Mental Health Problems: Behaviour, Self-Concept, Quality of Life and Family Functioning. Journal of Child \& Family Studies, 21, 262-272. http://dx.doi.org/10.1007/s10826-011-9471-2

Beasley, E. K., \& Garn, A. C. (2013). An Investigation of Adolescent Girls’ Global Self-Concept, Physical Self-Concept, Identified Regulation, and Leisure-Time Physical Activity in Physical Education. Journal of Teaching in Physical Education, 32, 237-252.

Bentler, P. M. (1990). Comparative Fit Indexes in Structural Models. Psychological Bulletin, 107, 238-246. http://dx.doi.org/10.1037/0033-2909.107.2.238

Bentler, P. M., \& Bonett, D. G. (1980). Significance Tests and Goodness of Fit in the Analysis of Covariance Structures. Psychological Bulletin, 88, 588-606. http://dx.doi.org/10.1037/0033-2909.88.3.588

Borges, V. R., \& Werlang, B. S. G. (2006). Estudo de ideação suicida em adolescentes de 15 a 19 anos (Study of Suicide Ideation in Adolescents from 15 to 19 Years Old). Estudos de Psicologia, 11, 345-351. http://dx.doi.org/10.1590/s1413-294x2006000300012

Boye, B., Lundin, K. E. A., Leganger, S., Mokleby, K., Jantschek, G., Jantschek, I. et al. (2008). The INSPIRE Study: Do Personality Traits Predict General Quality of Life (Short Form-36) in Distressed Patients with Ulcerative Colitis and 
Crohn's Disease? Scandinavian Journal of Gastroenterology, 43, 1505-1513. http://dx.doi.org/10.1080/00365520802321196

Browne, M. W., \& Cudeck, R. (1993). Alternative Ways of Assessing Model Fit. In K. A. Bollen, \& J. S. Long (Eds.), Testing Structural Equation Models (Vol. 154, pp. 136-162). Newbury Park, CA: Sage Focus Editions.

Bullinger, M. (2002). Assessing Health Related Quality of Life in Medicine: An Overview over Concepts, Methods and Applications in International Research. Restorative Neurology \& Neuroscience, 20, 93-101.

Bullinger, M., Von Mackensen, S., Fischer, K., Khair, K., Petersen, C., Ravens-Sieberer, U. et al. (2002). Pilot Testing of the "Haemo-QoL" Quality of Life Questionnaire for Haemophiliac Children in Six European Countries. Haemophilia, 8, $47-$ 54. http://dx.doi.org/10.1046/j.1351-8216.2001.114.doc.x

Butler, J. M., \& Haigh, G. V. (1954). Changes in the Relation between Self-Concepts and Ideal Concepts Consequent upon Client-Centered Counseling. In C. R. Rogers, \& R. F. Dymond (Eds.), Psychotherapy and Personality Change (pp. 55-75). Chicago, IL: University of Chicago Press.

Byrne, B. M. (1989). A Primer of LISREL: Basic Applications and Programming for Confirmatory Factor Analytic Models. New York: Springer-Verlag Publishing. http://dx.doi.org/10.1007/978-1-4613-8885-2

Chalem, E., Mitsuhiro, S. S., Ferri, C. P., Barros, M. C. M., Guinsburg, R., \& Laranjeira, R. (2007). Gravidez na adolescência: Perfil sócio-demográfico e comportamental de uma população da periferia de São Paulo, Brasil (Teenage Pregnancy: Behavioral and Socio-Demographic Profile of an Urban Brazilian Population). Cadernos de Saúde Pública, 23, 177-186. http://dx.doi.org/10.1590/S0102-311X2007000100019

Costa, P. T., \& McCrae, R. R. (1980). Influence of Extraversion and Neuroticism on Subjective Well-Being: Happy and Unhappy People. Journal of Personality and Social Psychology, 38, 668-678. http://dx.doi.org/10.1037/0022-3514.38.4.668

Craven, R. G., \& Marsh, H. W. (2008). The Centrality of the Self-Concept Construct for Psychological Wellbeing and Unlocking Human Potential: Implications for Child and Educational Psychologists. Educational and Child Psychology, 25, 104-118.

Cruzeiro, A. L. S., Silva, R. A. D., Horta, B. L., Souza, L. D. D. M., Faria, A. D., Pinheiro, R. T. et al. (2008). Prevalência e fatores associados ao transtorno da conduta entre adolescentes: um estudo de base populacional (Prevalence and Factors Associated with Behavioral Disorders in Adolescents: A Population-Based Study). Cadernos de Saúde Pública, 24, 20132020. http://dx.doi.org/10.1590/S0102-311X2008000900007

De Clercq, B., De Fruyt, F., Koot, H. M., \& Benoit, Y. (2004). Quality of Life in Children Surviving Cancer: A Personality and Multi-Informant Perspective. Journal of Pediatric Psychology, 29, 579-590. http://dx.doi.org/10.1093/jpepsy/jsh060

Erhart, M., \& Ravens-Sieberer, U. (2006). Health-Related Quality of Life Instruments and Individual Diagnosis-A New Area of Application. GMS Psycho-Social-Medicine, 3, 11.

Erhart, M., Ottova, V., Gaspar, T., Jericek, H., Schnohr, C., Alikasifoglu, M., the HBSC Positive Health Focus Group (2009). Measuring Mental Health and Well-Being of School-Children in 15 European Countries Using the KIDSCREEN-10 Index. International Journal of Public Health, 54, 160-166. http://dx.doi.org/10.1007/s00038-009-5407-7

Erikson, E. H. (1994). Identity: Youth and Crisis. New York: W.W. Norton \& Company.

Ferrans, C. E., Zerwic, J. J., Wilbur, J. E., \& Larson, J. L. (2005). Conceptual Model of Health-Related Quality of Life. Journal of Nursing Scholarship, 37, 336-342. http://dx.doi.org/10.1111/j.1547-5069.2005.00058.x

Fonseca, M. D. S. (2013). O estudo da influência da perturbação de hiperatividade com défice de atenção (PHDA) nas variáveis autoconceito e percepção de qualidade de vida em crianças com 10 a 12 anos de idade. Master's Dissertation, Coimbra: Faculdade de Psicologia e Ciências da Educação da Universidade de Coimbra.

Fornell, C., \& Larcker, D. F. (1981). Evaluating Structural Equation Models with Unobservable Variables and Measurement Error. Journal of Marketing Research, 18, 39-50. http://dx.doi.org/10.2307/3151312

Gaspar, T., \& Matos, M. G. (2008). Qualidade de vida em crianças e adolescentes: Versão portuguesa dos instrumentos KIDSCREEN-52. Cruz Quebrada: Aventura Social e Saúde.

Gaspar, T., Matos, M. G., Ribeiro, J. L. P., \& Leal, I. (2006). Qualidade de vida e bem-estar em crianças e adolescentes (Quality of Life and Well-Being among Children and Adolescents). Revista Brasileira de Terapias Cognitivas, 2, 47-60. http://dx.doi.org/10.5935/1808-5687.20060016

Gaspar, T., Ribeiro, J. L. P., Matos, M. G., \& Leal, I. (2008). Promoção de qualidade de vida em crianças e adolescentes (Quality of Life Promotion with Children and Adolescents). Psicologia, Saúde \& Doenças, 9, 55-71.

Gomes, M. C., \& Ribeiro, J. (2001). Relação entre o auto-conceito e bem-estar subjectivo em doentes cardíacos do sexo masculino sujeitos a cirurgia de bypass aorto-coronário (Relationship between Self-Concept and Subjective Well-Being in Male Patients Undergoing Coronary Artery Bypass). Psicologia, Saúde \& Doenças, 2, 35-45.

Hair Jr., J. F., Black, W. C., Babin, B. J., Anderson, R. E., \& Tatham, R. L. (2009). Análise Multivariada de Dados (Mul- 
tivariate Data Analysis) (6th ed.). Porto Alegre: Bookman.

Humensky, J. (2010). Are Adolescents with High Socioeconomic Status More Likely to Engage in Alcohol and Illicit Drug Use in Early Adulthood? Substance Abuse Treatment, Prevention, and Policy, 5, 19. http://dx.doi.org/10.1186/1747-597X-5-19

Jatobá, J. D. A. V. N., \& Bastos, O. (2007). Depressão e ansiedade em adolescentes de escolas públicas e privadas (Depression and Anxiety in Adolescents from Public and Private Schools). Jornal Brasileiro de Psiquiatria, 56, $171-179$. http://dx.doi.org/10.1590/S0047-20852007000300003

Jöreskog, K. G., \& Sörbom, D. (1984). LISREL-VI User's Guide (3rd ed.). Mooresville: Scientific Software.

Käppler, C. (2004). Access to Mental Health Care in Children (The AMHC-Study): Concepts of Mental Health and Perception of Services from the Perspective of Children, Adolescents and Their Families (4052-103375). Zürich: Zentrum für Kinder-und Jugendpsychiatrie der Universität Zürich.

Lemstra, M., Bennett, N. R., Neudorf, C., Kunst, A., Nannapaneni, U., Warren, L. M. et al. (2008). A Meta-Analysis of Marijuana and Alcohol Use by Socio-Economic Status in Adolescents Aged 10-15 Years. Canadian Journal of Public Health, 99, 172-177.

Levy, R. B., Castro, I. R. R. D., Cardoso, L. D. O., Tavares, L. F., Sardinha, L. M. V., Gomes, F. D. S., \& Costa, A. W. N. D. (2010). Consumo e comportamento alimentar entre adolescentes brasileiros: Pesquisa Nacional de Saúde do Escolar (PeNSE), 2009 [Food Consumption and Eating Behavior among Brazilian Adolescents: National Adolescent SchoolBased Health Survey (PeNSE), 2009]. Ciência \& Saúde Coletiva, 15, 3085-3097. http://dx.doi.org/10.1590/S1413-81232010000800013

Locke, K. D. (2006). What Predicts Well-Being: A Consistent Self-Concept or a Desirable Self-Concept? Journal of Social and Clinical Psychology, 25, 228-247. http://dx.doi.org/10.1521/jscp.2006.25.2.228

Lynch, M. (2004). Basic Needs and Well-Being: A Self-Determination Theory View. Psychology Journal of Higher School of Economics, 1, 137-142.

Lynch, M. (2014). The Self-Concept in Relationships. In N. Weinstein (Ed.), Human Motivation and Interpersonal Relationships (pp. 121-137). Dordrecht: Springer. http://dx.doi.org/10.1007/978-94-017-8542-6_6

Lynch, M. F., La Guardia, J. G., \& Ryan, R. M. (2009). On Being Yourself in Different Cultures: Ideal and Actual SelfConcept, Autonomy Support, and Well-Being in China, Russia, and the United States. The Journal of Positive Psychology, 4, 290-304. http://dx.doi.org/10.1080/17439760902933765

Marôco, J. (2014). Análise de Equações Estruturais: Fundamentos teóricos, Software \& Aplicações (2nd ed.). Pêro Pinheiro, Portugal: Report Number.

Martinez, C. J., Martin, A. J., \& Dowson, M. (2006). Investigating Self-Concept and Health-Related Quality of Life. Symposium Conducted at the Meeting of the Fourth International Biennial SELF Research Conference, Ann Arbor. http://researchdirect.uws.edu.au/islandora/object/uws:8741

Masthoff, E. D., Trompenaars, F. J., Van Heck, G. L., Hodiamont, P. P., \& De Vries, J. (2007). The Relationship between Dimensional Personality Models and Quality of Life in Psychiatric Outpatients. Psychiatry Research, 149, 81-88. http://dx.doi.org/10.1016/j.psychres.2006.01.004

McCrae, R. R., \& John, O. P. (1992). An Introduction to the Five-Factor Model and Its Applications. Journal of Personality, 60, 175-215. http://dx.doi.org/10.1111/j.1467-6494.1992.tb00970.x

Mead, G. H. (2009). Mind, Self, and Society: From the Standpoint of a Social Behaviorist. Chicago, IL: University of Chicago Press.

Morais, C. A. (2008). Saúde, doença mental e serviços de saúde na visão de adolescentes e seus cuidadores. Master’s Dissertation, Porto Alegre: Programa de Pós-Graduação em Psicologia, Universidade Federal do Rio Grande do Sul.

Morais, C. A., Amparo, D. M., Fukuda, C. C., \& Brasil, K. T. (2012). Concepções de saúde e doença mental na perspectiva de jovens brasileiros (Brazilian Young People Perceptions of Mental Health and Illness). Estudos de Psicologia (Natal), 17, 369-379. http://dx.doi.org/10.1590/S1413-294X2012000300004

Penedo, F. J., Gonzalez, J. S., Dahn, J. R., Antoni, M., Malow, R., Costa, P., \& Schneiderman, N. (2003). Personality, Quality of Life and HAART Adherence among Men and Women Living with HIV/AIDS. Journal of Psychosomatic Research, 54, 271-278. http://dx.doi.org/10.1016/S0022-3999(02)00482-8

Rajmil, L., Roizen, M., Psy, A. U., Hidalgo-Rasmussen, C., Fernández, G., \& Dapueto, J. J. (2012). Health-Related Quality of Life Measurement in Children and Adolescents in Ibero-American Countries, 2000 to 2010. Value in Health: The Journal of the International Society for Pharmacoeconomics and Outcomes Research, 15, 312-322. http://dx.doi.org/10.1016/j.jval.2011.11.028

Ravens-Sieberer, U., \& KIDSCREEN Group Europe (2006). The KIDSCREEN Questionnaires Quality of Life Questionnaires for Children and Adolescents. Lengerich: PABST.

Ravens-Sieberer, U., Erhart, M., Wille, N., Wetzel, R., Nickel, J., \& Bullinger, M. (2006). Generic Health-Related Quality- 
of-Life Assessment in Children and Adolescents: Methodological Considerations. Pharmaco Economics, 24, 1199-1220. http://dx.doi.org/10.2165/00019053-200624120-00005

Remschmidt, H., \& Mattejat, F. (1999). Familien-Identifikations-Test (FIT). Handanweisung. Göttingen: Hogrefe, Verlag $\mathrm{GmbH} \& \mathrm{Co}$.

Rodrigues, S. M. S. (2015). Relações entre Qualidade de Vida Relacionada à Saúde e Autoconceitos e Conceitos de Outros Significativos: Uma investigação teórica em amostra de adolescentes por meio da Modelagem de Equações Estruturais (Relations between Health Related Quality of Life and Self-Concepts and Concepts of Significant Others: A Theoretical Research in a Sample of Adolescents through Structural Equation Modeling.) Doctoral Thesis in Theory and Research of Behavior. Brazil: Universidade Federal do Pará.

Rodrigues, S. M. S., Almeida, S. D. S. D., \& Ramos, E. M. L. S. (2011). Suporte familiar e transtornos mentais comuns de adolescentes grávidas no município de Belém. (Family Support and Common Mental Disorders among Pregnant Teenagers). Psicologia Argumento, 29, 91-100.

Rodrigues, S. M. S., Pedroso, J. D. S., Pontes, F. A. R., \& Käppler, C. O. (2015). Measuring Health-Related Quality of Life in Adolescents by Subgroups of Students and Outpatient Mental Health Clients. Psychology, 6, 833-845. http://dx.doi.org/10.4236/psych.2015.67082

Rodrigues, S. M. S., Pedroso, J. D. S., Pontes, F. A. R., Käppler, C. O., \& Bucher-Maluschke, J. S. N. F. (2015). Patterns of Family Identifications in Adolescents from Different Backgrounds. Psychology, 6, 1516-1530.

http://dx.doi.org/10.4236/psych.2015.612148

Rogers, C. (2012). On Becoming a Person: A Therapist's View of Psychotherapy. New York: Houghton Mifflin Harcourt.

Rogers, C. R., \& Dymond, R. F. (1954). Psychotherapy and Personality Change. Coordinated Research Studies in the Client-Centered Approach. Chicago, IL: University of Chicago Press.

Sá, D. G. F., Bordin, I. A. S., Martin, D., \& Paula, C. S. (2010). Fatores de Risco para Problemas de Saúde Mental na Infância/Adolescência (Risk Factors for Mental Health Problems in Childhood/Adolescence). Psicologia: Teoria $e$ Pesquisa, 26, 643-652. http://dx.doi.org/10.1590/S0102-37722010000400008

Sacker, A., \& Cable, N. (2006). Do Adolescent Leisure-Time Physical Activities Foster Health and Well-Being in Adulthood? Evidence from Two British Birth Cohorts. The European Journal of Public Health, 16, 331-335. http://dx.doi.org/10.1093/eurpub/cki189

Seabra, A. F., Mendonça, D. M., Thomis, M. A., Anjos, L. A., \& Maia, J. A. (2008). Determinantes biológicos e sócioculturais associados à prática de atividade física de adolescentes (Biological and Socio-Cultural Determinants of Physical Activity in Adolescents). Cadernos de Saúde Pública, 24, 721-736. http://dx.doi.org/10.1590/S0102-311X2008000400002

Siegler, I. C., \& Brummett, B. H. (2000). Associations among NEO Personality Assessments and Well-Being at Midlife: Facet-Level Analyses. Psychology and Aging, 15, 710-714. http://dx.doi.org/10.1037/0882-7974.15.4.710

Solans, M., Pane, S., Estrada, M. D., Serra-Sutton, V., Berra, S., Herdman, M. et al. (2008). Health-Related Quality of Life Measurement in Children and Adolescents: A Systematic Review of Generic and Disease-Specific Instruments. Value in Health, 11, 742-764. http://dx.doi.org/10.1111/j.1524-4733.2007.00293.x

Tanaka, J. S., \& Huba, G. J. (1985). A Fit Index for Covariance Structure Models under Arbitrary GLS Estimation. British Journal of Mathematical and Statistical Psychology, 38, 197-201. http://dx.doi.org/10.1111/j.2044-8317.1985.tb00834.x

Taquette, S. R., Vilhena, M. M. D., \& Paula, M. C. D. (2004). Doenças sexualmente transmissíveis na adolescência: Estudo de fatores de risco (Sexually Transmitted Diseases in Adolescence: Study of Risk Factors). Revista da Sociedade Brasileira de Medicina Tropical, 37, 210-214. http://dx.doi.org/10.1590/S0037-86822004000300003

Tavares, B. F., Béria, J. U., \& Lima, M. S. D. (2004). Fatores associados ao uso de drogas entre adolescentes escolares (Factors Associated with Drug Use among Adolescent Students in Southern Brazil). Revista de Saúde Pública, 38, 787796. http://dx.doi.org/10.1590/S0034-89102004000600006

Teixeira, S. A. M., \& Taquette, S. R. (2010). Violência e atividade sexual desprotegida em adolescentes menores de 15 anos (Violence and Unsafe Sexual Practices in Adolescents under 15 Years of Age). Revista da Associação Médica Brasileira, 56, 440-446. http://dx.doi.org/10.1590/S0104-42302010000400017

Teodoro, M. (2000). Habilidades sociais e processos de identificação em crianças e adolescentes. Master’s Dissertation, Belo Horizonte: Universidade Federal de Minas Gerais.

Van De Ven, M. O. M., \& Engels, R. C. M. E. (2011). Quality of Life of Adolescents with Asthma: The Role of Personality, Coping Strategies, and Symptom Reporting. Journal of Psychosomatic Research, 71, 166-173. http://dx.doi.org/10.1016/j.jpsychores.2011.03.002

van Straten, A., Cuijpers, P., van Zuuren, F. J., Smits, N., \& Donker, M. (2007). Personality Traits and Health-Related Quality of Life in Patients with Mood and Anxiety Disorders. Quality of Life Research, 16, 1-8.

http://dx.doi.org/10.1007/s11136-006-9124-x

Veiga, G. V. D., Cunha, A. S. D., \& Sichieri, R. (2004). Trends in Overweight among Adolescents Living in the Poorest and 
Richest Regions of Brazil. American Journal of Public Health, 94, 1544-1548. http://dx.doi.org/10.2105/AJPH.94.9.1544

Yamaoka, K., Shigehisa, T., Ogoshi, K., Haruyama, K., Watanabe, M., Hayashi, F., \& Hayashi, C. (1998). Health-Related Quality of Life Varies with Personality Types: A Comparison among Cancer Patients, Non-Cancer Patients and Healthy Individuals in a Japanese Population. Quality of Life Research, 7, 535-544. http://dx.doi.org/10.1023/A:1008830509237

Ybrandt, H. (2008). The Relation between Self-Concept and Social Functioning in Adolescence. Journal of Adolescence, 31, 1-16. http://dx.doi.org/10.1016/j.adolescence.2007.03.004 